6. Lowry, O. H., Roschrough, N. J., Farr, A. L... and Randall, R. J.: Protcin meisutement with the Folin phenel reagent. J. Biol. (hem., 193: 205 (1951).

7. Rennert. (). M., Frias, J., and LaPointe, D.: In: J. A. Mangos: Fundamentat Problems of Cystic Fibrosis and Related Discases. 0 p $41-52$ (Intcrountinental Medical Books, New York, 1973).

8. Rennert. O., Garnica, A., and Chan, W. Y.: Hyperornithinemia and hyperammonemia: A rare disorder of ammonia metabolism. In: R. Preisig. J. Bircher, and (9. Paumgartner: The Liver, Ouantitative Aspects of Structure and Function, p. 298 (Editor Cantor, Aulendorf, 1976).

9. Remnert, ().. Miale, T., Shukla, J., Lawson, D., and Friats, J.: Polvamine concentrations in bone marrow aspirates of children with leukemia and other malignancies. Blond, 47: 695 (1976)

10. Richards, G. M.: Modifications of the diphenylamine reaction giving increased sensitivity and simplicity in the estimation of 1$) \mathrm{NA}$. Anal. Biochem. 57 : $3(6)(1974)$.
11. Russell, D) 11.: Function of Naturally ()corring Polyanines (Academic Prens. New York, London. 1973)

12. Russell. D. H.: Polyamines in Normal and Neoplastic (irowth (Raven Press. New York, 1973)

13. Russell, D. H., and NeVicher, T. A.: Polvamines in the developing rat and in supportive tissues. Biochem. Biophys. Act:a, 25y: 247 (1972)

14. This work was supported in part by National Institutes of Health Training Grant AMOS6SO-(1) and research grants from the National Cystic Fibrosis Research Foundation and the Bochringer Mamneim Corporation.

15. This proposal was approved by the Institutionat Human Experimentation (ommittee and skin biopsies were obtained with informed censent.

16. Requests for reprints should be addressed to: (). N. Remert, M.D). Department of Pediatrics. Box J29). University of Florida (allege of Medicine. Gainesville, Ha. 32610) (USA)

17. Reccived for publication May 21, 1976.

18. Accepted for publication September 2, 1976.

Copyright + 1977 International Pediatric Research Foundation, Inc.

Printed in U.S.A

Pediat. Res. 11: 19()-197 (1977)

\title{
A Review: Newer, Noninvasive Cardiac Diagnostic Methods
}

\author{
WILLIAM F. FRIELMAN, (6ii) DAVID) J. SAHN, AND MICHAIE, J. HIRSCHKLAU
}

Division of Pediatric Cardiology, Departme'nt of Pediatrics, University of California, San Dicgo, School of Medicine, La Jolla. Colifornia, and the Department of Pediatrics, University of Arizema Schosl of Medicine, Tucism, Arizona, USA

This review article will focus on the application of awo noninvasive techniques that have become increasingly more useful in the diagnosis and management of infants and children with heart disease. In a general sense, noninvasive diagnostic techniques provide two types of information; first, one secks anatomic information in order to more clearly describe the architectural details of the heart and circulation, and, second, one hopes to derive data allowing analysis of functional characteristics of the circulation. The ability to obtain important structure-function correlations by the use of both scintillation scanning and cardiac ultrasound forms the basis for their widespread applicability in noninvasive diagnosis. IVe will describe selected aspects of current applications of scintillation scanning of the lungs and heart and of echocardiography, and will attempt to indleate new and interesting directions that may be anticipated by continuing developments in these fields. We await, with interest, additions to the armamentarium of the diagnostician that may be expected in the future from electrocardiographic-gated. computerized axial tomograms of the heart and from flow velocity data provided by range-gatted, pulsed Doppler technology.

It should be understood that noninvasive metheds infrequently offer a substitute for invasive hemodynamic and angiographic studies performed in the cardiac catheterization laborattory. Rather, the former most often provide valuable ancillary datat that assist the clinician appreciably in decisions concerning pationt management.

\section{SCINTILLATION SCANNING}

Isotopes are employed to quantify the distribution of pulmonary blood flow in patients with a wide variety of acequired and congenital heart discise in order to determine indirectly the levels of pulmonary venous and arterial pressures $(12,13)$ and to determine the patency of systemic arterial and systemic venouspulmonary arterial anastomosis (9.12). In addition to these lung scanning methods which employ radionuclide labeled macroaggregated human serum albumin, radionuclide angiography is utilized to view alterations in the anatemy of the heart and great vessels, and to detect and quantify keft to right, intrat, or extratcardiac shunts $(2-4,22,33,35)$. The latter studics are performed after intravenous infusion of $99^{\mathrm{m}}$ technetium with a scintillation camera coupled to a computer tape storage system.

\section{ALTHRATIONS IN REGIONAL PULMIONARY BLOOD ILOW}

\section{VERTICAL DISTRIBUTION OF ILOW}

The distribution of pulmonary blood flow vertically or to either lung may be determined in an accurate and reproducible manner by scintillation scanning of the lungs (12). The rationale for evaluating the vertical distribution of pulmonary blood flow resides in the importance of distinguishing patients with both pulmomary arterial and venous hypertension from those with pulmonary arterial hypertension alone.

In this regard, more precise selection may be anticipated of patients repuiring an accurate hemodynamic assessment of pulmonary flows and resistance. It is recognized that because of the influence of gravity on the low pressure vascular bed, nomal crect subjects have greater blood flow to the lung bases than to the apices. In patients with pulmonary venous hypertension. there is a relative increase in blood flow to the apices and a dec ease in perfusion to the lung bases. A linear relationship 
exists between the magnitude of the shift of blood flow toward the apices and the level of mean left atrial pressure (12). When pulmonary blood flow increases, as it does in patients with left to right cardiac shunts, the normal difference in flow between the upper and lower pulmonary zones decreases, even if the pulmonary artery pressure remains normal (13). Patients with left to right shunts with pulmonary arterial hypertension and without pulmonary venous hypertension show a further reduction in the difference in flows between the apical and dependent zones of the lungs. When both pulmonary arterial and venous pressure rise, blood flow to the apices of the lung increase's whereas flow to the bases diminishes, and the result is an inversion of the pattern observed in normal erect subjects.

Thus, the evaluation of the vertical distribution of pulmonary blood flow may be of especial aid in pre-and postoperative situations in which pulmonary venous hypertension may he a problem. In this regard. we have used this method to sereen patients with pulmonary hypertension for potentially correctable lesions such as cor triatriatum and mitral stenosis, and to serially evaluate patients after mitral valve surgery for acquired or congenital lesions of the mitral valve in postoperative patients with endecardial cushion malformation, and most recently, after Mustard operation in those patients with transposition of the great arteries in whom pulmonary venous obstruction may result from the interatrial baffle.

\section{DISTRIBUTION OF FIOW TO BO'TH LUNGS}

An analysis of the distribution of pulmonary blood flow to both lungs may also be of assistance in clinical management. In the normal subject, the distribution of blood flow to the right lung is $5.3 \pm 2.3 \%$ (SI) $)(13)$. It has been noted recently that in some paticnts with transposition of the great arteries, pre-and/ or post-Mustard operation scintillation scans of the lungs may show a remarkable reduction in isotope accumulation to the left lung $(8,42,6(0)$. It is not yet known with eertainty whether all postoperative patients with this finding show a similar abnomal preoperative distribution of pulmonary flow. The markedly asvmmetric distribution of flow to both lungs likely results from the altered spatial orientation of the main pulmonary artery and clongation of the course of the left pulmonary artery favoring How to the right lung $(8)$.

The combination of xenon-133 lung ventilation-perfusion scan and technetium-99 madionuclide angiograms has been shown recently to be of importance to assess changes in pulmonary ventilation and perfusion pre- and postoperatively and to evaluate intracardiac shunting or atrial baffle obstruction postoperatively (42).

Studies of patients with tetralogy of Fallot pre- and postsystemic-pulmonary arterial shunting have demonstrated that, although total pulmonary blood flow is increased after a systemicpulmonary anastomosis, the augmented flow to the lung on the side of the anastomosis may be largely composed of oxygenated shunted blood. whereas the flow to the opposite lung is largely unsaturated systemic venous blood (13). In addition, a patent shunt changes the distribution of blood entering the main pulmonary artery from the right ventricle, diverting most of the sy'stemic venous return to the lung on the side opposite the anastomosis. Xenon-1.33 ventilation studies may be performed in these same patients (1). Since the distribution of ventilation most often remains symmetric, some patients are noted to have significant ventilation perfusion imbalance. Moreover, subseyuent operative correction of the tetralogy anomaly may not result in the restoration of normal ventiation-perfusion relationships (1). These observations lend support to the single stage surgical correction approach, rather than the palliative followed by repair approach to surgical management.

\section{RAIDIONUCLIDE ANGIOGRAPHY}

This technique utilizes an Anger scintillation camera that detects the passage through the heart and lungs of a radioactive bolus of intravenously administered technetium-99"'. Polaroid exposures are used to demonstrate flow through the central circulation. The camera output is atso fed directly into a dedicated computer-controlled system and recorded on digital magnetic tape. This system allows review of the complete sequence so that Polaroid prints can be obtained at desired intervals and also permits selection of one or more anatomic areas of interest from which the analog tracings of changing count rate, which is equivalent to flow. may be plotted as a function of time. Upon replay of recorded data, these areas of interest may be positioned clectronically to correspond to a cardiac chamber of great vessel or a portion of either lung. In the latter position. radionuclide pulmonary time actvity, or vascular "dilution curves." may be inscribed $(2,3,22,35)$.

When radionuclide angiography is used to evaluate the antatomic details of cardiovascular malformations, the radioisotopes images, in general, reflect the findings observed by standard contrast angiocardiography. Although the sequential radioisotope images do not provide the salme degree of fine detail as $x-$ ray angiocardiograms, many altered intra- and extracardiac flow patterns can be identified and the compromise in image resolution may be acceptable since it is balaneed by the simplicity. speed, and safety of the method $(22,33)$. In contrast to angiography, the isotope images do not provide the fine anatomic details required preoperatively to plan surgical repair of anomalics.

\section{SHUNT DETECTHON}

Radionuclide angiography finds its widest application in the detection and quantification of left to right shunts. As mentioned above, the key to these analyses is provided by the inscription of pulmonary vascular isotope histograms. In our initial studies we employed a count ratio technique to analyze pulmonary vascular isotope dilution curves (22). It was clear that the absolute presence or absence of a shunt could be predicted with great aceuracy with this technicue, whereas the precise magnitude of the shunt was less well predicted in the absence of ancillary clinical data. Subsequently, wo area ratio techniques have been employed to calculate shunt size from a ratio of areas under the pulmonary time activity curve. The areas are defined by fitting a mathematical function to the original data. One method uses a Steward-Hamilton extrapolation of the downslope of the curve (3), whereas the other employs $\gamma$ function fitting of the pulmonary activity curve $(35)$. A precise evaluation of the accuracy of the count ratio and two area ratio techniques have been performed (2). The count ratio technique did not adequately discriminate patients with shunts from those with either congestive heart failure or valvular regurgitation lesions in whom false positive results were obtained occasionally. Both area ratio techmigues obviated this problem. Shunt quantification appears to be most accurate when the $\gamma$ function algorithm is employed. Although the $\gamma$ function method gives a higher correlation with oximetry than exponential fitting, the former requires a computer to extract the shunt recirculation curve from raw data. Thus, the $\gamma$ function method seems desirable for those hospitals witl appropriate computer facilities, whereas the exponential fitting methed provides a use ful alternative in other situations.

The applicability of a noninvasive echnique to estimate shunt size in postoperative patients is self-evident. In patients who have undergone operative closure of their shunts, postoperative catheterizations may be avoided if the scanning method clearly indicates the absence of a residual shunt. Shunt detection and quantification is also of practical importance to screen and distinguish that large group of patients suspected of having left to right shunts from those patients with other forms of heart disease or insignificant functional murmurs. Moreover, the method may be employed to follow serially patients who may experience spontaneous closure of their shunts and those in whom a serial estimate of the magnitude of left to right shunting maldetect the onset of pulmonary vascular obstructive discase. 
It should be recognized that the scamning techniques described in the present report impose little rish or discomfort to the patient. Since radiation exposure to the patient is remarkably low when compared with cineangiocardiography, the techniques can be serially applied in pationt management.

\section{EOHOCARIOHOGRAPHY}

The most exciting new approach in the noninvasive evaluation of heart discase in infants and children is provided by ultrasound cardiography or echocardiography. This major advance has already had significant impact upon the practice of pediatric cardiology, and, indece, it maty be anticipated to substantially enhance diagnostic and management capabilities in the future.

\section{SINGLIE CRYSTAL IECHOCARIOIOCRAPHY}

Until recently, only single crystal echocardiographic techniques were used by pediatric cardiolegists. With continuous recording techniques and high frequency transducers data have been collected defining the range of nomal for the dimensions and motions of the great vessels and cardiate structures in infants and children $(16,20,56)$, to evaluate cardiac performance by analyses of a bost of indices of myocardial contractile and pump function $(19,25,28,43,46,62)$, detect and assess the magnitude of intercitculatory shunting $(5,7,10,29,34,39,40)$, $41,49,50,52,53,55,58,59,64)$, to analyze the severity of left ventricular outflow tract obstructive lesions $(15.27,54.6 .3)$ and the levels of pulmonary pressures (26), and, of course, to derive information concerning the anatomy of the heart, perse $(16,37$. $38,45,57)$. The latter area especially has been the subject recently of comprehensive reviews and will not be dealt with in the current discussion. We have chosen to be selective and will focus our remarks upon the application of single crystal techniques to serial assessment of left to right shunts across a patent ductus arteriosus in the premature or newborn infant, to the combination of echocardicgraphy and saline contrast techniques for the assessment of right to left and left to right intracardiac shunting, and to the derivation of systolic time intervals and the ir combination with ejection phase parameters of cardiac performance for the evaluation of cardiocirculatory function.

\section{PATENT DUC"TUS ARTIERIOSUS IN PRIENATURI: OR NIEWBORN INFANIS}

Left atrial size, which may be measured accurately by echo, is increased in patients with left to right shunts distal to the atrioventricular valves. Serial analysis of the left atrium to aortic root dimension ratio $(\mathrm{L} / \mathrm{A} / \mathrm{AO})$ was shown intially by Silvermanet al. (55) to detect alterations in the magnitude of left to right shunting across a patent ductus arteriosus. Our laboratory $(49,50)$ and others $(5,7,39,64)$ have shown that appropriate directional changes in the $L A / A O$ ratio accompany both medical and surgical maneuvers that alter the magnitude of shunting and have established the fact that serial determinations of left atrial dimension are of major assistance in patient management. Mlost recently, for example. we have used the serial analysis of the $\mathrm{L} A / \mathrm{A}$ o ratio to confirm ductal clesure induced by inhibition of prostaglandin synthesis in a group of respirator bound, prematture babies with respiratory distress syndrome and clinical evidence of large volume, left to right shunting across the ductus (14).

Left atrial size determined in conjunction with simplified measures of alterations in heft ventricular performance, either the mean velocity of circumferential fiber shortening (mean $V(F)$ or fractional shortening of the left ventricle, have also proved of immense benefit in diagnostically separating infants without a congenital cardiocirculatory malformation but with signs of cardiac failure (hypoglycemia, sepsis, myocarditis, hypoxemia) from those with large left to right shunts $(49,50)$. Necdless to sily, the distinction between these two groups of
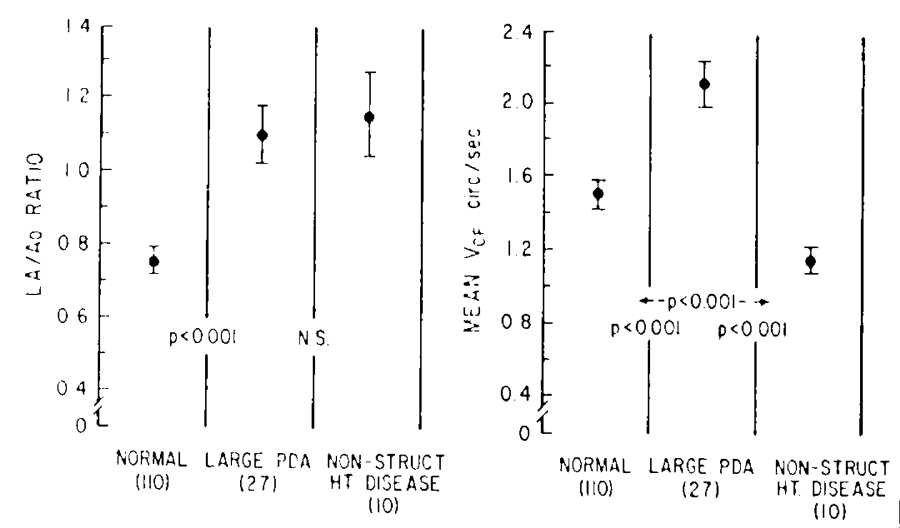

Fig. 1. The echociardiegraphically derived ratio between left atrium and antic root dimension $(/ . A / A \sigma)$ is significanty less in normal premature and full term newborns than in those with a large patent ductus arteriosus $(P D) .1)(P<0.0(1)$ or in those with nomstructural heart discase. The mean rate of left ventricular circumferential tiber $\left(V_{t r}\right)$ shortening is significantly higher than normal in infants with a large left to right shunt across a patent ductus arteriosus $(P<0 .(0) 1)$, and significantly lower than normal or ductus infants in the presence of depressed mocardial function $(P<0.0(0)$ ). The numbers in brachets refer to the number of infants from whom values were obtanined.

infants is offen necessary in the management of ill newborns. The mean VCF is abnormally clevated in infants with a large ventricular or ductal shunt, even in the presence of cardiac fature (Fig. 1), and both mean VCF and the shortening fraction of the left ventricle are significantly lower than normal in infants with nonstructural heart disease (Fig. 1). The latter infants, however, have a substantial augmentation in left atrial volume and size when compared with normal infants and LA/Ao ratios comparable with newhorns with large shunts (Fig. 1). Thus, the infants with cardiate dystunction, but witheut a congenital cardiocitculatory malformation, have a high $L A / A 0$ ratio and low mean VCF or extent of ventricular shortening. whereas the infants with left to right shunts have clevations in all indices. Both groups can therefore be distinguished from each other and from normal sulejects.

\section{HCHO(ARDIOGRAPHI ANI) SALINE CONTRASI}

Initially, the echoes produced by injection of indecyanine green dye were used as markers to identify the source of intracardiac echoes $(11,17)$. For example, during cardiac catheterization the selective, rapid injection of indocyanine green dye produced ultrasonic opacification by microbubble formation and one could follow the passage of the ultrasound opaque stream as it traversed cardiac chambers. It has now been demonstrated that normal saline or the pationt's own blood after injection into the peripheral or entral venous system or into a great artery or cardiac chamber mal identify a site of intercirculatory shunting $(10,29,40,41,52,53,58,59)$. For example, in the postoperittive patient with tetralogy of Fallot, saline injected into the superior vena cava produces echoes in right atrium and right ventricle. If the echoes are seen to cross the ventricular septum and enter left ventricle, it is clear that a residual right to left ventricular shunt exists. Figure 2 is an illustration of how the principle of saline contrast opacification may be used in the newborn period. The technicue will most likely have its widest application in the postoperative period in recognizing residual shunts at the bedside and may be of additional utility in differentating cardiac from noncardiac causes of cyanosis in critically ill newborns.

\section{ANALYSIS OF PULMONARY HIEMODYNAMIC'S ANE (OBSIRUC"IIVE LISSIONS}

Analysis of cardiac valve motions allows measurement of systolic phases of the cardiac cycle without the necessity of 

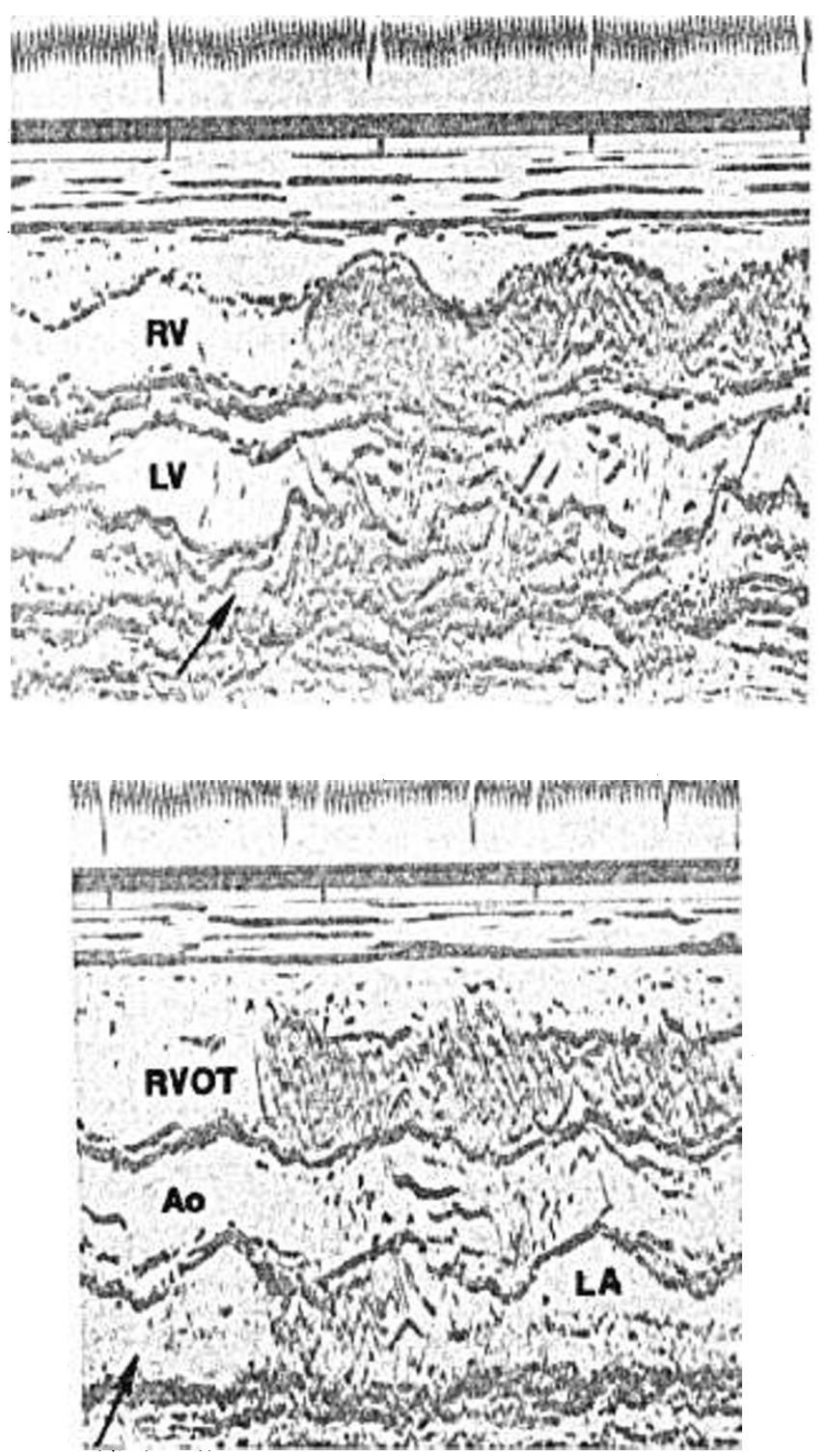

Fig. 2. Echo opacification identifies a right to left atrial shunt after saline injection into the umbilical vein of an infant with a patent foramen ovale catheterized for exchange transfusion. In the upper panel, left ventricular $(L V)$ opacification occurs initially from behind the mitral valve (arrow) just before opacification of the right ventricle $(R V)$. Since the echoes appear from behind the mitral valve rather than across the ventricular septum directly, the shunt is at the atrial level. In the lower pancl, imaging at the level of the aortic root (Ao) shows the early echo opacification of the left atrial cavity $(L A)$ (arrow') and later fill of both the aorta and the right ventricular outflow tract (RVOT).

externally recording the carotid pulse and the apex cardiogram. Whereas the latter graphic methods to determine systolic time intervals were employed traditionally to assess left ventricular function, echocardiography has been employed recently to derive timing information relative to the pulmonary circuit, which is, of course, unavailable from external pulse recordings. A good correlation has been shown to exist between pulmonary artery pressure and the pre-ejection period and ejection time measurements derived by echoes from the pulmonary valve (26). Thus, a ratio of right ventricular pre-ejection period to right ventricular ejection time of less than $(0.30$ is almost always associated with low pulmonary vascular resistance and low pulmonary arterial pressure, whereas a ratio greater than $0.4(0$ almost always indicates elevated mean pulmonary pressures and a pulmonary vascular resistance in exeess of 5 units. The latter measurements in association with loss of the $\Delta$ wate of the pulmonary valve echo trace and the presence of premature systolic closure of this valve appear to be accurate marters for the presence of pulmonary vascular obstructive discasc (Fig. 3).

There are now several promising echo applications that aim to assess the severity of aortic stenosis. Thus, it has been shown that determination of left ventricular ejection time corrected for heart rate correlates with the peath systolic pressure difference across the left ventricular outilow tract (54). An excellent correlation has also been found with the severity of stenosis using echocardiographic measurements of end systolic wall thichness and left ventricular cavity transverse dimension, and utilizing a normalized value for left ventricular systolic wall stress (15). Of course, the measurement of left ventricular wall thickness in these patients provides an index of the degree of cardiac hypertrophy created by the obstructing lesion. Thus, it would appear that echocardiography offers a noninvasive method for estimating and predicting the severity of left ventricular outflow tract obstruction that is substantially more sensitive than other currently employed techniques.

\section{CROSS-SECTIONAL ECHOCARIDIOGRAPHY - ANATOMIC DIAGNOSIS}

Despite the utility of single crystal techniques, they, nonetheless, provide only a "flashlight beam" section of the heart and may not allow an accurate assessment of the spatial orientation of intracardiac structures. Thus, the data provided by single crystal echocardiography in the presence of complex alterations in intra-and extracardiac architecture are oiien difficult to interpret objectively. Needless to say, it is precisely in those patients with the most complicated cardiac malformations that the pediatric cardiologist would value a reliable noninvasive means to alssist in diagnosis.
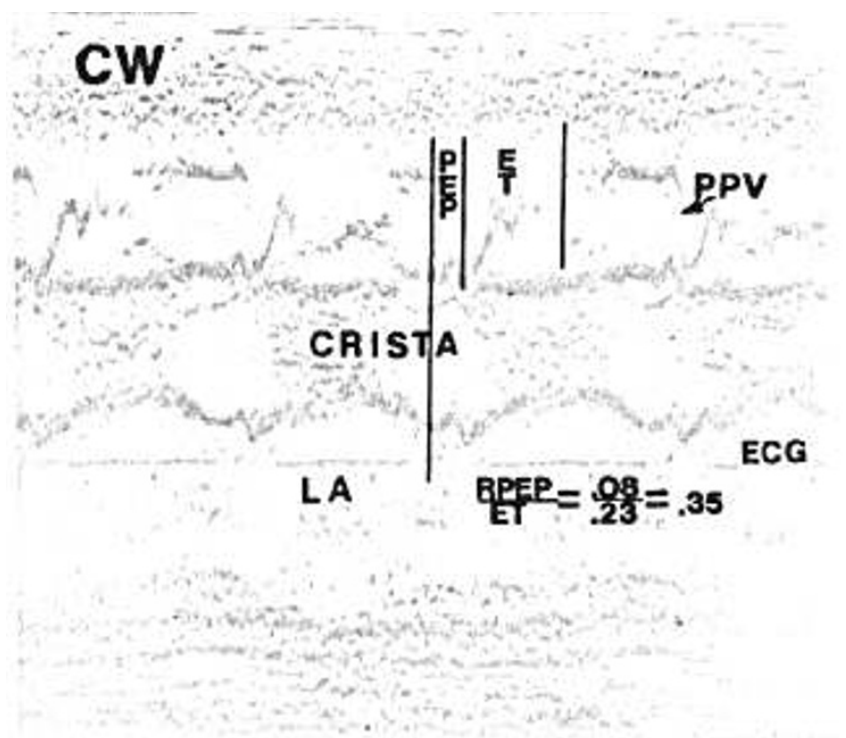

Fig. 3. Pulmonary valve echogram from a patient with a ventricular septal defect and pulmonary vascular obstructive disease illustrates flattening of the diastolic slope, absence of a presystolic opening motion ("a" (atrial) wave) and premature systolic clesure of the posterior pulmonary valve (PPV) cusp followed by a partial reopening. The right ventricular pre-ejection period (RPEP) and ejection time (ET) as well as the RPEP/ET ratio may be calculated from the pulmonary valve trace and the electrocardiogram $(E C G)$. Beat to beat variability in cusp registration and in the duration of pulmonary valve opening (beats 1 and 3 vs. 2 and 4) may be observed occasionally, perhaps due to respisation. CIV: chest wall; LA: left atrium. 

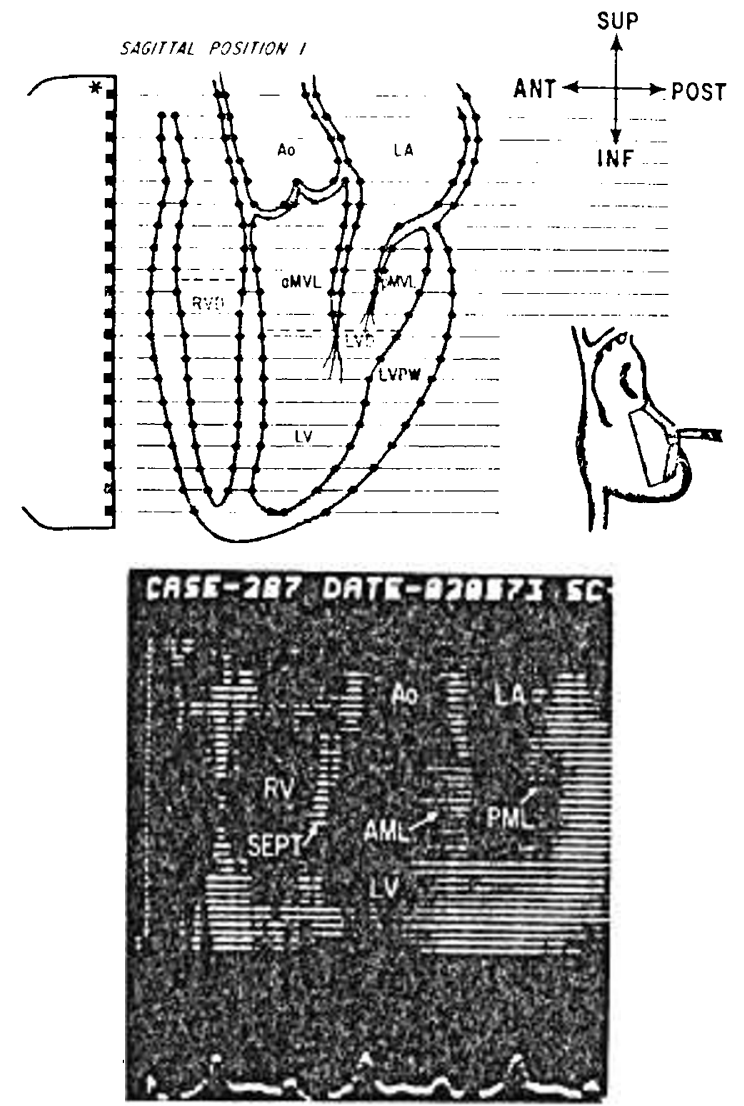

Iig. 4. Normal multixcan sagintal cross-section. Transclucer alignment and image orientation (top), and polaroid phots (boltom). The first clement in the transdacer $\left(^{*}\right)$ is superior. RV: right ventricle: SIPPI: ventricular soptum; Ao: aorta; I.V: left ventrick: L.A: left atrium; AML, aNVI : anterior mitral valve leaflet; PNIL. pMVL: pesterior mitral value keaflet: I.VPW: keft ventricular poskerior wall; RV1): right ventricular dimension, the latgest secen in ficld; L.VI): left ventricular dimension. at the kesel of the keatding edge of the AMIL. Repreduced by permission of Amcrican Iteart Association, Inc.. from Salne et al. (50).

Recently, cross-sectional techniques have been developed that provide a real time. two dimensional format that allows a substantially cuhanced appreciation of spatial intrat-and extraciardiac structural interrelationships. Cross-sectional methods incluke single crystal stop-action lechnigues (30, 31) and those that allow real time observations by single $(18,32,61)$ or multiple crystal devices (6). Stop-action technicues are not particularly applicable to the study of infints and children who maty not remain inumobile during the course of stidy. Motion studies in real time using single crystat scanning methods provide excellent resolution of structures, although the angle of the scamming are limits the size of the cardiac cross-section. linear array, multicrystal systems provide a large cross-section, but the size of the individual transducess restricts ultasonic penctration and sharp resolution of deep structures. Technologic advances are occurring at at rapid rate and it has become clear that the crosssectional approach, irrespective of the exact methodology utilized, greatly facilitates the noninvalsive assessment of congenital heart discase since definition is enhanced of greal dessel orientattion. cardiac chamber position, and outflow trate anatomy.

\section{MULIISCAN CROSS-SH ("IIONAL IECHOCARI)IOGRAPHY}

We have had extensive experience in the use of sagrital and transverse cross-sectional carliac imaging with the multiple arstal (multiscan) method in craluating the sites of heft ventriculat outfow tract obstruction (6.3). endecardial cushion defect (47). the common forms of cyanotic cardiate malformations ( 48$)$. left to right shunt kesions (21), and tricuspid and mitral valve abmor- malities $(21,44)$. Using a $4.5 \mathrm{MHz} 20$ element transducer, w have evaluated cardiac cross-sectional anatomy in a systemati manner using two saggital and wo transverse views (47). Figur t shows a long axis saggital view of the heart of a normal subject Four transducer positions are specifically designed to pro. vide visualization of the relative sizes of the right and left ventri cles in saggital section, longitudinal vistatization of the aseend ing aorta, visualization of tricuspid-pulmonary relationships, vis ualization of the size and course of the main pulmonary artery and visualization of the spatial orientation of the arorta ane pulmonary artery in transverse and saggital views. The eche identification of intra- and extracardiac structures in multipls cross-sectional planes has been validated by viewing cathete echoes and the passige of indocyanine green dye in patients witl congenital heart discase during their hemodynamie study (51).

The multiscan technique is especially suitable for defining great artery and cardiac chamber orientation and position. In the normal individuat, the great arteries have a spiral relationship ts one another and in the transverse plane one observes the righ ventricular outfow tract and pulmonary artery wrapping aroune the aorta from right to left so that the pulmonary artery lies te the keft and anterior of the atorta (Fig. 5). Nost importantly, it patients with D-transposition of the great arteries, the aortal mas be observed to ascend retrosternally, in marked contrast to the normal posterior sweep of the pulmonary artery (48). In trans. verse cross-section in I )-transposition paticnts the great arterie: do not have the normal spiral relationship to one another and the anterior atorta may be seen to lie to the right of the posterion pulmonary artery (4s) (lig. (6).

In paticnts with tetralogy of Fallot the most important feature secon by multiscan is a disruption of anrtic-septal continuty witl preservation of mitral-atortic continuity. Moreover, one mas almost always detect an enlarged ascending aorta which overricks the vertricular septum $(48)$. The findings in patients with truncus arteriosus are quite similar to those in tetralogy, althengh a pulmonary antery may not be identified. In addition, in patients with truncus arteriosus, one may suspect the diagnosis by observing multiple and unusual cusp echoes within the truncal root, probahly reflecting an abnormal number of cusps of the trumeal valve $(48)$. The distinctive findings in pattents with endecarclial cushion defect consist of multiple echoes in the mitral value area, anterior mitral leaflet-septal apposition in diastole

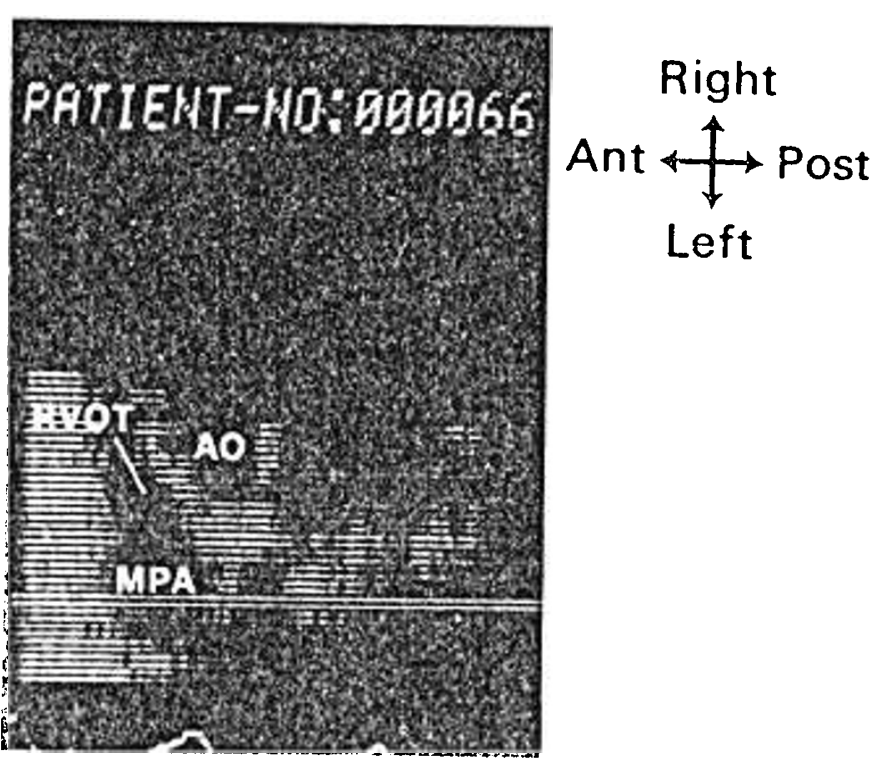

Fig. S. Normal great wessel oricntation: transwerse. Polaroid still france from the multiple-cristal system illustrates the spiral rebationstip of the right sentricular ouflow tract $(R V O) T$ ) and main pulmonary artery (MVPA) wrapping from right to keft around the posterior aorta (Ao) in a transerese cardiate cross-section at the second intercostal space. 
with reduced posterior motion in systole, and reduced excursion of the anterior mitral leaflet (47). In patients with the complete form of atrioventricular canal defect, the anterior leaflet may be observed passing across the plane of the ventricular septum into

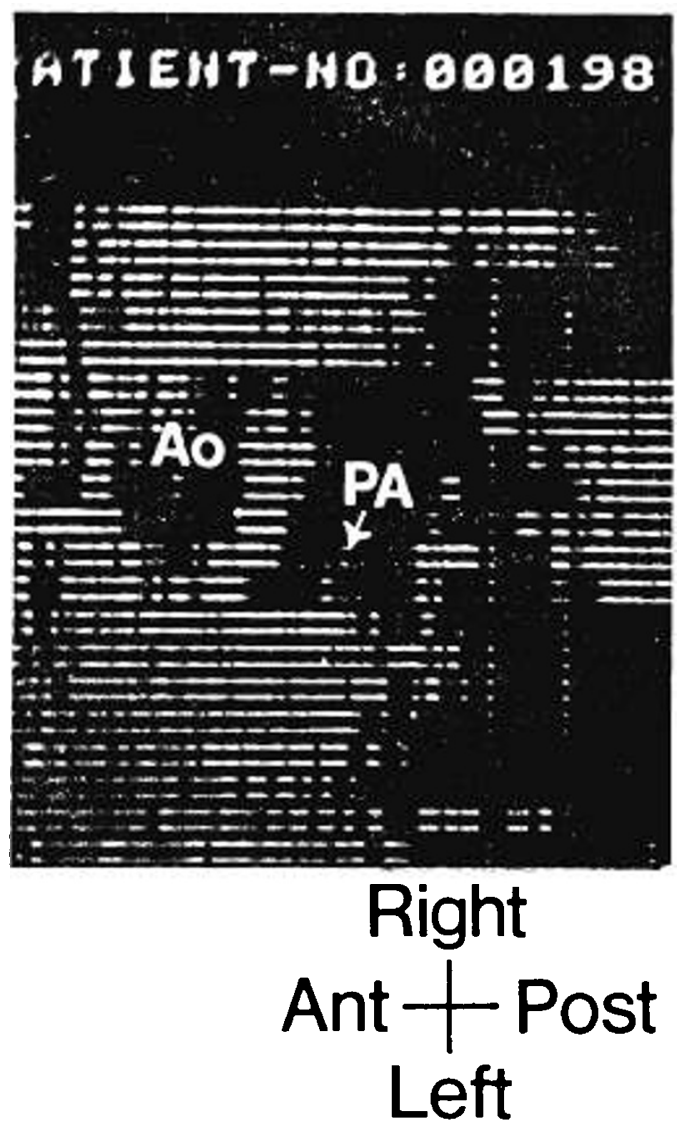

Fig. 6. Altered spatial relationship between aorta $(A O)$ and pulmonary artery $(P A)$ in an infant with $D$-transposition. The aorta lies to the right and anterior and the spiral relationship between the vessels is absent. the right ventricle during diastole, and, in some of these patients, the anterior mitral leaflet appears to be related to the tricuspid annulus.

Diagnostic findings are present in the various forms of left ventricular outflow tract obstruction (63). In patients with valvar aortic stenosis the aortic leaflets often appear thickened and display an unusual superior mobility with decreased lateral mobility. Poststenotic dilation of the ascending aorta is easily identified with the cross-sectional method. The findings in patients with discrete subvalvar aortic stenosis include a localized thickening in the ventricular septum at its insertion into the anterior wall of the ascending aorta just below the level of the valve. In patients with subaortic stenosis as a result of a parachute deformity of the mitral valve, one can visualize the anterior and posterior mitral leaflets related to one large papillary muscle. In the presence of supravalvar aortic stenosis, the ascending aorta shows an hourglass narrowing superior to the point at which aortic valve motion may be visualized. In patients with idiopathic hypertrophic subaortic stenosis, increased septal thickness and systolic apposition of the anterior mitral valve leaflet to the ventricular septum may be seen obstructing the left ventricular outflow tract.

\section{SECTOR SCANNING CROSS-SECTIONAL ECHOCARDIOGRAPHY}

High resolution ultrasound images of cardiac cross-sections are now being obtained utilizing either the mechanical motion of a single transducer to provide a real time sector scan $(18,36)$ or by systems employing phased array principles to rapidly steer the ultrasound beam through the structures under investigation in order to obtain a high quality tomograph image in real time (32, 61). Electronically steered phased array sector scanning has not yet been applied to problems in pediatric cardiology.

Recently, mechanical sector scanning in the transverse plane has been shown to aid greatly in the evaluation of atrioventricular valve morphology (24). Earlier studies reported a "fish mouth" shape of the mitral valve orifice in transverse sections and suggested further that the size of the mitral orifice could be assessed accurately (23). An extension of these studies in patients with cardiac malformations has shown that transverse plane cross-sectional imaging at the level of the junction of the atrial and ventricular septa allows analysis of complex morpho-
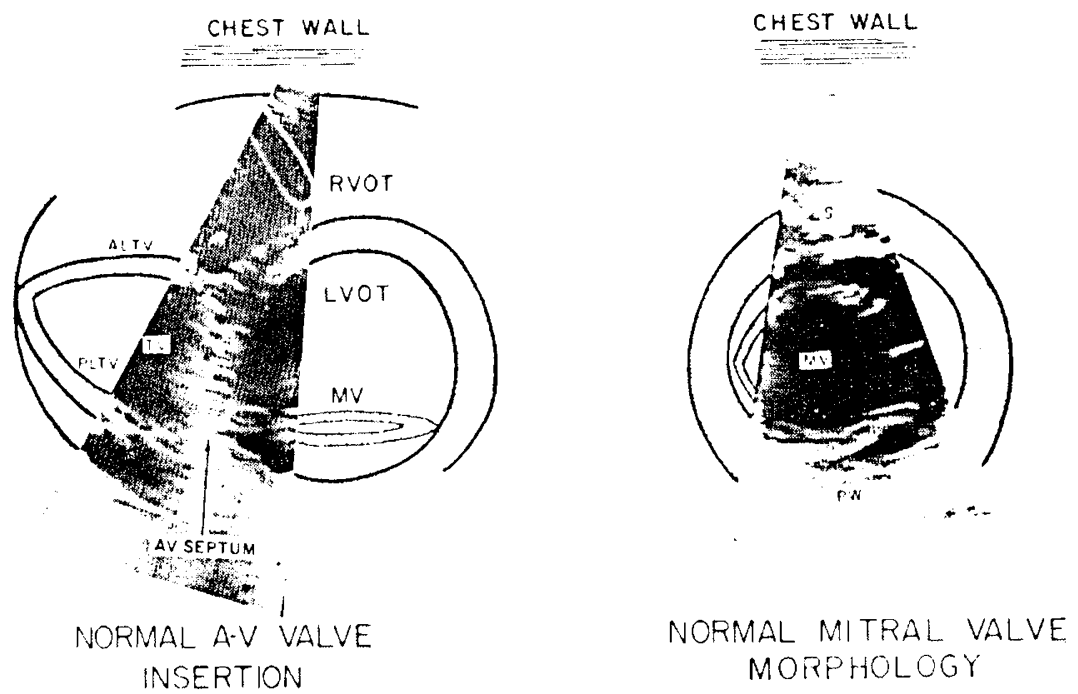

Fig. 7. Normal atrioventricular valve (A-V) morphology imaged with the sector scamning system. Imaging is in the transverse plane of the heart. The images are oriented differently from the multiscan illustrations (i.e., chest wall is at the top, right-sided structures are at the left side of each image, and left-sided structures are at the right). The left panel shows $A-V$ valves at the level of the atrioventricular septum. The insertions of the anterior $(A L T V)$ and posterior leaflets $(P L T V)$ of the tricuspid valve $(T V)$ are shown relative to the insertion of the mitral valve (MV). RVOT: right ventricular outflow tract; LVO'T: left ventricular outflow tract. An electrocardiogram artifact is seen anteriorly on this image. In the panel the normal fish mouth appearance of the mitral valve is shown in transverse section at the level of the valve orifice. 
logic changes involving both the mitral and tricuspid valves, and maty, indecel, allow the determination of ventricular situs. This is of especial advantage since conventional single crystal echo techniques have not heretofore allowed the examiner to distinguish the morphologic characteristics of mitral from tricuspid valve. Thus, the technigue promises to be of great value in patients with ventricular inversion and L-transposition of the great arteries in whom the mitral valve guards the right-sided ventrick, and in patients with various forms of endocardial cushion defect. Figure 7 provides an illustration of normal atrioventricular valve morphology as imaged by the mechanical sector seamning systcm.

Cross-sectional echo by sector scanning may not only allow the determination of the actual size of the mitral valve orifice, but may also prove of value in the assessment of the severity of acrtic stenosis. The measurement of maximum aortic cusp separation during long axis cross-sectional scanning of the aortic valve, related to the echocardiographically determined diameter of the aortic root at the valve level, appears to provide an index that correlates well with the severity of obstruction (27).

It secms clear that single crystal, and especially cross-sectional echocardiographic approaches, irrespective of the exact method employed, will enjoy their widest application as initial tests to establish diagnosis, as precathelerization studies to more appropriately plan the course of subsequent hemodynamic investigation, and as methods for serially evaluating patients in whom anatomic findings and their functional conseyuences may change with time. Furthermore. it is evident that echocardiography is applicable to large numbers of patients and provides clinically important information to assist in the diagnosis and management of infants and children with diverse forms of heart discase.

\section{REFERINCES ANI) NOTISS}

1. Alderson, P. O., Boomvisit, S., Mcknight, R. C.. and Hartman, A. F., Jr.: Pulmonary perfusion abmormalities and ventilation-perfusion imbalance in childen after total repair of tetralogy of Fallot. Circulation, 53: 332 (1976).

2. Alderson, P. O., Jost, R. G., Strauss, A. W., Boonvisit. S. and Markham. J. Radionuclide angiocardiography: Improved diagnosis and quantitation of left-(o)-right shunts in children using area ratio techniques. Circulation. 51: $1136(1975)$.

3. Anderson, P. A. W., Jones, R. H., and Sabiston, D. C.: Quantitation of leftlo-right cardiate shunts with radionuclide angiography. (irculation, 4\%: 512 (1974).

4. Askenazi, J., Ahnberg, D. S., Korngold, I.. LatFarge, C. G., Maltz, D. L.. and Treves, S.: Quantitative radionuclide angiocardingraphy: Detection and quantitation of left to right shunts. Amer. J. (ardiol.. 37: 382 (1976)

5. Baylen, B. G.. Meyer, R. A., Kaplan. S. Ringenburg, W. E.. and Korfhagen, J.: The critically ill premature infant with patcont ductus arteriosus and pulmonary discase - An echocardingraphic ansessment. J. Pediat., 86: 423 (1975).

6. Bom, N. Lancee, C. R., vanZwieten. (;., Kloster, F. E., and Roclandt, J.: Nultiscan echocardingraphy. I. Technical description. Circulation, $78: 1060$ (197.3).

7. Canter, W. H., and Bowman, C. R.: Istimation of shunt flow in isolated ventricular septal defect by echocardiogram. (irculation, 77: (14 (197.3).

8. Conway, J. J., and Muster. $\dot{A}$. J.: Pulmonary perfusion distribution in transposition of the great arteries. J. Nucl. Mcd., 15: $48+(1974)$

9. 1)raulens-Noc, HI. A., and Evenbly, H.: The value of radioisetope scimning in the study of pulmonary circulation in patients with tetralogy of Fallot and systemic pulmonary anastomosis. J. Nucl. Biol. Mc.l., 16: 145 (1972)

10. Duff, D. F., and Gutgesell, H. P.: The use of saline for ultrasonic detection of a right-o-left shunt in postoperative period. Amer. J. Cardiol., 37: 132 (1976).

11. Feigenbaum, H., Stone, J. M. Lee, D. A. Nasser. W. K., and Change, S. ldentification of ultrasound echoes from the left ventricle by use of intracardiac injections of indocyanine green. Circulation, 41: 615 (1970).

12. Firiedman. W. F.. and Braunwald, E..: Alterations in regional pulmonary blood flow in mitral valve disease studied by radioisotope scanning. (irculation. 34: $36.3(1966)$.

13. Friedman, W. F., Bratunwald, E... and Morrow, A. G.: Alterations in regional pulmonary blood flow in patients with congenital heart discase studied by radioisotope scaming. Circulation, 34: $747(1968)$

14. Friedman, W. F., Hirschklau, M.J., Printz, M. P., Pitlick, P. T., and Kirkpatrick, S. E.: Pharmacologic closure of patent ductus in the premature. $N$ Engl. J. Med. 295: 526 (1976).

15. Glanz, S., Hellenbrand, W. E., Berman, M. A.. and Talner, N. S.: Echocardiographic determinations of ventricular dimensions: Use in atortic stenosis. Pediat. Res., /0: 312, (1976)

16. Goldberg, S. J., Allen, H. D., and Sahn, D. J.: Pediatric and Adelescent
Echocardiography: A Handbook (Yearbook Medical Publishers, Chicago, $1975)$.

17. Gramiak, R., Shah, P. M., and Kramer, D. H.: Ultrasound cardiography: Contrast studies in andomy and function. Radiology, 92: 939 (1969).

18. Griffith, J. M., and Henry, W. L.: A secter scanner for real time, twodimensional echocardiography. (irculation, f9: 1147 (1974).

19. Gutgesell, H. P., Paquet, M., Duff, E. F., and M.Namara, D. G.: Left ventricular function in normal children: Fiffects of age and heart rate. Circulation, 52: 9 (1975)

20. Hagan, A. D., Decly, W. J., Sahn, D. J., Fricdman, W. F.: Echecardiographic criteria for normal newborn infants. Circulation, 48: 1221 (1973).

21. Hagan, A. D.. Francis, G., Sahn, D. J., Karliner, J., Friedman, W. F., and O'Rourke, R.: Ultrasound evaluation of systolic anterior septal motion in patients with and without right ventricular volume overload. Circulation, 50: $248(1974)$.

22. Hagan, A. D., Friedman, W. F., Asbburn, W. C. Alazraki, N.: Further application of scintillation scanning technigues to the diagnosis and management of infants and children with congenital heart discase. (Circulation, 5.5 $858(1972)$.

23. Henry, W. L., Griffith, J. M., Michaclis, L. L., M.Intosh, C. L. Morrow, A G.. and Epstein, S. I:.: Measurement of mitral orifice area in patients with mitral valve disease by real-time, lwe-dimersional echocardiography. Circulation, 5I: $827(1975)$.

24. Henry, W. L., Sahn, D. J., Griffith, J. M., Goldherg, S. J., Maron, B. J., MeAllister, H. A., Allen, H. D., and Epstein, S. E.. IEvaluation of atrionentricular valve morphology in congenital heart disealse by real-time crosssectional echocardiography [Abstract]. Circulation, 52: 120 (1975).

25. Hirschfeld, S., Meyer, R., Schwartz, D). C., Korfhagen, J., Kaplan, S.: Measurement of right and left ventricular systolic time intervals by echocardiography. Circulation, 51: 304 (1975).

26. Hirschfeld, S., Meyer, R., Schwartz, I). C., Korfhagen, J., and Kaplatn, S.: The echocardiographic assessment of pulmonary artery pressure and pulmonary vascular resistance. Circulation, $52: 042(1975)$.

27. Hurwitz, R. A., Weyman, A. I., Ieigenbaum, H., Girod, 1). A., Dillon, J. C.. and Stewart, J.: Cross-sectional echocardiographic assessment of severity of aortic stenosis in children. Amer. J. Cardiol., 37: 1.44 (1976).

28. Johnson, G. L., Meyer, R. A., Korfhagen, J., and Kaplan, S.: Echographic evaluation of left ventricular function in childen with aortic stenosis. Circulation, 52: 199) (1975)

29. Kerber, R. I., Kioschos, J. M., and Latuer, R. M.: Use of an ultrasonic contrast method in the diagnosis of valvular regurgitation and intracardiac shunts. Amer. J. Cardiol.. 34: 722 (1974)

30. King. 1). 1..: Cardiac ultrasonography: A stop action echniguc for imatging intracardiac anatomy. Radiolingy. 103: 387 (1972)

31. King, D. L.: Cardiac ultrasonography: (ross-sectional ultrasonic imaging of the heart. (irculation. 47: 843 (1973).

32. Kissle, J., vonkamm, (). T., and 'Thurstone, F. L.: Cardiac imaging using a phased array ultrasound system. II. Clinical technique and application. (irculation, 53: 262 (1976)

3.3. Kriss, J. P.. Enright, L. P., Hayden, W. G., Wexler, L., and Shumway, N. E.: Ratelensotope angiocardiography: Wide scope of applicability in diagnosis and evaluation of therapy in disease's of the heart and great vessels. Circulation. 43: 792 (1971)

34. Lewis, A. B., and Takahashi, M1.: Echocardiographic assessment of left-ter right shunt volume in children with ventricular septal defect. Circulation 54: $78(1976)$.

35. Maltz. D. L... and lreves. S.: Ouantitative radionuclide angiocardiography: Determination of (2p:()s in children. (irculation, 47: 1049 (1973).

36. Maron. B. J.. Henry, W. F., Griffith, J. M., Freedom, R. M. Kelly, I). T. and l:pstein. S. E.: Jentification of congenital malformations of the great arteries in infants by real-time twordimensional echocardiography. Circulation. 52: 671 (1975)

37. Neyer, R. A.. and Kaplan. S.: Noninvasive technicues in cardiovascular disease. Progr. Cardiovasce. Dis., $15: 341,(1973)$.

38. Meyer, R. A., Schwartz, D). C., Covitz, W., and Kaplan, S.: Echocardiographic atssessment of cardiac malposition. Amer. J. Cardiol.. 33: 896 (1974).

39. Neyer. R. A., Stockert, J., and Kitplan. S.: Echographic determination of left ventricular volumes in pediatric patients. (irculation, 51: 297 (1975)

40. Pieroni, D. R., Valdes-(ruz. L. M.: Differentiation of cyanosis in the newhorn by contrast echocardiegraphy techniques. Amer. J. Cardiol., 37: 162 (1976).

41. Picroni, D., Varghese, P. J., Rowe, R. D.: Echocardiography to detect shunt and valvular incompetence in infants and children. Circulation, 48: 81 (1973)

42. Rabinovitz, M., Rosenthal, A., Salk, R. M., Nadas, A. S., Castenada, A. R., and Treves, $S .:$ Xenon-133 lung ventilation-perfusion scans, and technetium-99"' radionuclide angiograms in patients with D-transposition of the great arteries. Amer. J. Cardiol., 37: 16.3 (1976).

43. Sahn, D. J., Allen. H. D.. and Goldberg. S. J.: The comparative utility of echocardingraphic indices for the detection of depressed left ventricular function in children. Amer. J. Cardiol., 37: 168 (1976).

44. Sahn, D. J.. Allen, H. I). Goldberg. S. J. and Friedman, W. F.: Mitral valve prolapse in children: A problem defined by real time cross-sectional echercardiegraphy. Circulation, 53: 6.51 (1976).

45. Sahn, D. J., Allen. H. D.. Goldberg, S. J., Solinger, R., and Meyer, R. A.: Pediatric echocardiography: A review of its clincial utility. J. Pediat. 87 $3.35(1975)$.

46. Sahn, D. J., Decly, W. F., Hagan, A. D., and Fricdman, W. F.: Echocardi- 
ographic assessment of left ventricular performance in normal newborns. Circulation, 49: $232(1974)$.

47. Sahn, 1). J., Terry, R., O'Rourke, R., Leopold, G.. and Fricdman, W. F.: Alutiple crystal echocardiographic evaluation of endecardial cushon defect. Circulation, 50: 25 (1974).

48. Sahn, D. J., Terry, R., ORourke, R., Leopold, G., and Friedman. W. F. Multiple crystal cross-sectional echocardiography in the diagnosis of $\mathrm{cy}$ anotic congenital heart disease. (irculation, 50: 230)(1974)

49. Sahn, D. J. Vaucher, Y. Williams, D. L., Allen, H. D., Goldberg, S. J., and Fricdman, W. F.: Echocardiographic detection of large left-to-right shunts and cardiomyopathies in infants and children. Amer. J. Cardiol.. 38: 73 (1976).

50. Sahn, D. J., Vaucher, Y.. Williams, D, E., and Friedman, W. F.: Ficho distinction of left-to-right shunts from non-structural heart discase (NID)) in infancy. Circulation. 50: $16(1974)$

51. Sahn, D. J.. Williams, D. E., Shackelton, S., and Friedman, W. F.: The validity of structure identification for cross-section echocardiography. J Clin. Ultrasound, 2: $201(1974)$

52. Seward, J. B.. Taijik, A. J., Spangler, J. G.. and Ritler, D. G.: Echocardiographic contrast studies: Initial experience. Mayo Clinic Proc.. 5/: 6.3 (1975).

53. Ritter, D. G.: Contrast echocardiegraphy: Peripheral vein injection of indecyanine green dse for detection and assessment of right-to-left intracardiac shunting. Amer. J. Cardiol., 37: 171 (1976)

54. Silverman. N. H., French, J. W.. Wallington, J.. and Popp, R. L.: Echocardiographic evaluation of the severity of valvar aortic stenosis in children. Pediat Res. 10. 316 (1976)

55. Silverman, N. H., Lewis, A. B., Heymann. M. A., and Rudolph, A. M. Echocardiographic assessment of ductus arteriosus shunt in premature infints. (irculation, 50: $821(1974)$
56. Solinger, R.. Elbl, F., and Minhas, K.: Echocardiography in the normal neonate. Circulation, 47: $108(1973)$.

57. Solinger, R.. E:1bl, F., and Mlinhas, K.: Deductive echocardiographic analysis in infants with congenital heart disease. Circulation, 50: 1072 (1974)

58. Valdes-Cruz, L. M., Pieroni, D. R., Roland, J. M., and Shematek, J. P. Recornition of residual postoperative shunts by contrast echocardiographic techniques. Amer. J. Cardiol.. 37: 178 (1976).

59. Valdes-Cruz, L. M., Pieroni, D. R., Roland, J. M. A.. and Varghese. J.: Echocardiographic detection of right-to-left shumts by peripheral vein injections. Circulation, 52: 121 (1975).

60) Vidne, B. Duszynski, D., and Subramanian, S.: Pulmonary flow distribution in transposition of the great arteries. Amer. J. Cardiol., 37: 178 (1976).

61. vonRamm, O. T., and Thurstone. F. L.: Cardiac imaging using a phased ultrasound system. I System design. Circulation, 53: 258 (1976).

62. Vredevere L. A Creckmere S. P S shiller N B. The measurement of systolic time intervals by echocardiography. J. Clin. Ultrasound, 2: 99 (1974).

63. Williams, D). E.. Sahn, D. J., and Friedman, IV. F.: (ross-sectional echocardiographic localization of sites of left ventricular outflow tract obstruction. Amer. J Cardiol. 37: 250 (1976)

(44. Yabek, S. M., Isabel-Jones, J., Bhatt, D. R., Nakazawa, M., Marks, R. A and Jarmakani, J. M.: Echocardiographic determination of left atrial volumes in children with congenital heart disease. Circulation, 53: 268 (1976)

65. This research was supported by United States Public Health Service Grants HL 12373, HL 05846, and HL 17334.

66. Requests for reprints should be addressed to: W. F. Friedman, N.1). Chief of Pediatric Cardiology, University Hospital, 225 West Dickinson St.. San Diego. Calif. 92103 (USA)

67. Reccived for publication June 21, 1976

68. Accepted for publication September 2, 1976
Alveolar macrophages surfactant differentiation lamellar myelin lysosomes

\title{
Maturation of the Rabbit Alveolar Macrophage during Animal Development. I. Perinatal Influx into Alveoli and Ultrastructural Differentiation
}

\author{
BARBARA J. ZELIGS"G:" LATA S. NERURKAR, AND JOSEPH A. BELLANTI \\ D'parme'nts of Pediatrics, Microbiology, and the' ('nter for Interdisciplinary Studic's of Immunology at \\ Georgetom, Georgeton't University School of Medicine, Washington, D.C., USA
}

JOSEPH D. ZELIGS

Laboratory of Molecular Biology, Natonal Cancer Instiute, National Institutes of Health, Bethesda, Marylanci, USA

\section{Summary}

Rabbit alveolar macrophages (AM's) were collected by tracheobronchial lavage at sequential times during animal development. The total number of cells recovered by this technique was found to increase markedly shortly before birth (Fig. 4). This apparent influx of macrophages into the alveoli continued during the first postnatal week, and, at a reduced rate, throughout the first postnatal month of life (Fig. 3).

Ultrastructurally, AN's of the prenatal period resembled their monocyte precursors, and contained modest numbers of lysosomes and mitochondria, scant lamellae of ribosome-studded endoplasmic reticulum (RER), and a small Golgi apparatus (Fig. 12). $A$ considerable amount of phagocytosed material was observed in these AM's, and consisted largely of cellular debris and two forms of surfactant-related phospholipids, termed tubular and lamellar myelin (Figs. 12-15). The quantity of these ingested phospholipids increased dramatically shortly after birth, in correlation with the known release of similar material from type II pneumocytes at this time. (Figs. 16 and 19).

During the first postnatal week ANI's showed a considerable increase in number of mitochondria and in the development of the RER and Golgi apparatus (Fig. 22). Increased accumulations of lipid droplets were also noted during this period. Ingested material continued to consist largely of surfactant-related phospholipids, but was less abundant at this time.

By 28 days after birth, AMI's were nearly morphologically mature (Fig. 25). They showed large numbers of lysosomes and mitochondria, and well developed RER and Golgi apparatuses. Ingested phospholipid material was still visualized, and the in- 